\title{
Using Food Grate Stainless Steel Rods for Internal Fixation of Transverse Fractures in Rabbits
}

\author{
Humam H Nazht* \\ Department Surgery and Obstetric, College of Veterinary Medicine, University of \\ Baghdad, Iraq \\ *Corresponding author: Humam H Nazht, Department Surgery and Obstetric, \\ College of Veterinary Medicine, University of Baghdad, Iraq, Tel: 009647901784013; \\ Email: Humam_nazhat@yahoo.com
}

\section{Research Article \\ Volume 4 Issue 3}

Received Date: August 16, 2019

Published Date: October 29, 2019

DOI: $10.23880 /$ oajvsr-16000188

\section{Abstract}

This project was designed to replace the medical stainless steel pins (MSP) which used in internal fixation of the transverse fractures femoral bone in rabbits by the food grate stainless steel rods (FGSR) 2.25 and $2.5 \mathrm{~mm}$ which used in the food industry. 175 adult local breed rabbits were used from 2008-2019, 60 of them used to induced transverse fractures in the mid shift of femoral bones, the others employed to remove $1 \mathrm{~cm}$ of diaphysis bone and replaced by either xeno-bony sheep implantation in 26 rabbits, or replaced by xeno-bony bovine implantation in 75 rabbits, while the others14 rabbits replaced by the synthetics bony nano scaffold implantation, then all fixed by FGSR as internal fixation devices for the induced femoral fractures or fixation the implanted devices. The parameters which were used for evaluation were, the physical and general examination, laboratory analysis for elements ratio, clinical application with radiographic and histopathological examination. The results revealed FGSR easy to find and use and handling, with low prize and high economic values, and the chemical elements ratio the same as in the MSP, nobody rejection or complication, not changed before and within and after implantation and sterilization, give stability, and support the body weight, and the rabbits quickly used affected limb in walking and running, the FGSR visible radio graphically with good alignment of fractures bones with normal healing radiographic finding, while the histopathological examination shows normal histopathological changes during fractures healing processing. The conclusion FGSR size $2.25-2.5 \mathrm{~mm}$ can be used strongly and successfully in internal fixation of induced transverse mid shift fractures of femoral bones in rabbits instead of the MSP.

Keywords: Food Grate Stainless Steel Rod (FGSR); Medical Stainless Steel Pins (MSP); Induced Transverse Fractures 
Abbreviations: MSP: Medical Stainless Steel Pins; FGSR: Food Grate Stainless Steel Rods; IM: Intramedullary Nailing.

\section{Introduction}

Fracture is a medical condition in which the continuity of the bone is broken. Mostly due to high force, or some medical conditions that weaken the bones, as in osteoporosis, bone cancers, or ontogenesis imperfect [1]. Many improvements in the internal fractures fixation methods and technique and selection different types of implants and grafts of small animal have been done [2-4]. Classically, methods of internal fracture fixation like pins, wires, screws, and bone plates with screw, that lead to stabilized fractures, and minimized surrounding soft tissue trauma and promote biologic osteosynthesis [5-7].

Intramedullary nailing (IM) fixation has become the stander of treatment for both femoral and tibial shift fractures, for its success results, easy and less traumatic, used to align and stabilize fractures $[8,9]$.

IM pinning is a surgical procedure used to stabilize a broken bone by inserting a metal rod in the hollow modularly canal of the bone, to hold the rod and allow for early movement and weight bearing, and often the preferred treatment for fractures of the lower extremity long bones that are not close to the joints (bone ends) In these cases, patients can resume walking much sooner than with other types of fracture treatment [10].

The advantages of IM pinning is, Easy to use, low cost, Less of bone exposed comparing with other methods, minimal tissue damage and distraction, do not need to support it with the external fixation, do not lead to deformity or loss the function of the affected limbs or any joint stiffness $[7,11,12]$. Jonathan Cluett mentioned in 2018 that there is Sufficient strength to carry body weight, and that is why people can often place weight on the extremity sooner than if you had to wait for full healing of the bone. IM implants rod is made of stainless steel or titanium and come in different lengths and diameters to fit patients of different ages and heights, with several advantages, including lower mechanical failure rates and improved [11,13], they don't really speed bone healing or take the place of bone healing, because any metal implant used to stabilize a fracture is designed to hold the fracture in proper alignment while the normal healing process takes place.

In others hand many disadvantage of using IM pinning for internal fixation as mentioned by Frik, et al. [13] and
Slatter, et al. [14] like improper immobilization, with circulation movement, bone marrow destruction and infection due to microorganism, Osteomylitis may occurs, loss the pins, Loss in stable fixation, slower return to function, the healing by Secondary bone union, and more involved after care, it cannot be used for all fractures, a second operation may be needed to remove the IM device if you have painful symptoms. Otherwise, the IM rod is designed to stay inside your bone forever.

Because of the Number of the scientific research of both post graduated and under graduated students in veterinary medicine college/university of Baghdad and college of science /Al-Mustanseria university which depend on the rabbits especially in orthopedic surgery so the great need for internal fixation methods especially size 2.25-2.5 mm, in other hand the MSP or titanium not easy to find, with its high cost, so this problems must be ended and looking for another internal fixation methods in rabbits, so the aim of the presents study is to attempted to replace the MSP which used in the internal fixation devices for the femoral fractures in rabbits by FGSR used in food industry and easy to find and handling, with its low cost.

The parameters that used for evaluation which followed to $3-6$ months p. 0 .

1. Physical and general examination

2. Laboratory analysis for elements ratio.

3. Clinical observation during surgical implantation of the FGSR in fractured

4. Radiographic finding of using FGSR in internal fixation of fractures

5. Histopathological examination.

\section{Materials and Methods}

\section{FGSR Preparation}

The FGSR which prepared from the local market is about $100 \mathrm{~cm}$ length, and $2.25-2.5 \mathrm{~mm}$ in diameter (Figure 1), they cut to about 10- 11 pieces each of $9-10$ $\mathrm{cm}$, they well cleaned and washed (Figure 2), while the MSP is about $30 \mathrm{~cm}$, can be cut to three piece only, then the proximal end prepare to sharp point and the distal end to chisel point of each piece (Figure 3A).

The Physical and General Properties: After cleaning and well washing the FGSR sterile in three different methods, by, boiling water, heat with pressure and steam (Figure 3B), and by cold sterilization with $70 \%$ medical ether alcohol or 2\%.tincture of iodine They kept for grossly observation for any changes or oxidation or corrosion may occurs after sterilization for different time, 
day 0 immediately after sterilization, and 1,3,7,30,90 days, 6 months, 1 , and 2 years after sterilization

Laboratory Analysis for Element Ratio: A piece of both the FGSR and the MSP were send to the al-Nahrain university physical laboratory for analysis of element ratio composition.

Clinical Application: The clinical application was done by using FGSR as internal fixation device of the following surgical operation:

1. Transverse complete fractures in the mid shift of the femoral bones in 60 rabbits which fixed by FGSR (Figure 4).

2. Transverse complete fractures in the mid shift of the femoral bones with removing $1 \mathrm{~cm}$ of bone and replaced by $1 \mathrm{~cm}$ xeno- sheep bony implantation the fixed with FGSR in 26 rabbits (Figure 5).

3. Transverse complete fractures in the mid shift of the femoral bones with removing $1 \mathrm{~cm}$ of bone and replaced by $1 \mathrm{~cm}$ xeno- bovine bony implantation the fixed with FGSR in 75 rabbits.

4. Transverse complete fractures in the mid shift of the femoral bones with removing $1 \mathrm{~cm}$ of bone and replaced by $1 \mathrm{~cm}$ synthetic bony nano scaffold implantation and fixed with FGSR (Figure 6).

The Radiographic Examination: During fractures healing processing which monitored radio graphically weekly to follow the radiographic changes. At the mediolateral and anterio- posterior vie at $\mathrm{Kv}=47-53, \mathrm{MaS}=2.20$ 6 , F.F.D $=30 \mathrm{~cm}$.The $\mathrm{x}$-ray machines type ECO-RAY Korea manufactured.

The Histopathological Examination: The histopathological changes were monitored during healing processing. The bone specimen were prepared from the euthanized rabbits and kept in buffered formalin for fixation then processed in decalcification solution and prepared paraffin blocks and slides.

\section{Results}

\section{The Results of the Physical and General Proprieties}

The food grate stainless steel rods of $100 \mathrm{~cm}$ length can be prepared to $10-11$ pieces each of length $9-10 \mathrm{~cm}$. while the medical stainless steel pinning of $30 \mathrm{~cm}$ length can be cutting to 3 pieces (Table 1).

> Both can be sterile by boiling water, heat with pressure and steam, and cold sterilization.
No change occurs before and after sterilization when kept for months and years after sterilization (Figure 7A).

$>$ Easy to find, low prize, easy to handle and prepare of the FGSR, while MSP high prize not easy to find but easy to handle and prepare.

$>$ The FGSR not changed when remove after radiological and clinical union (Figure 7B).

\section{The Results of the Laboratory Analysis}

The elements ratio which found in the FGSR the same or near the normal ratio of the MSP (Figure 8) (Table 2).

\section{The Results of the Clinical Application}

$>$ The inflammatory signs begin within the first day and ended at the 5-7 day p. o. (Figure 9).

$>$ the animals hold the affected limb within the first week, at the end of the 1st week p. o. the animals can bear the body weight when standing and hold the limb during waking then at the end of the 2nd week p. o. the animals can bear the weight during walking and in standing position, at the end of the 3rd week p. o. the animals normally used the limb in bearing the weight and walking and running

$>$ When remove the internal fixation of both the FGSR and MSP after clinical union the animals can normally use the limbs.

$>$ using both types of internal fixation give good support for the limb to use it normally and quickly

$>$ Nobody rejection or any complication were occurs during healing processing

\section{The Results of the Radiographic Finding}

All the radiographic signs revealed good alignment of the fracture fragments (Figure 10). With sclerotic area around fracture line, periosteal reaction with new bone formation at the end of the 2 nd week p. o. Which later increase in volume and density, at the 4th week p. o. fracture line disappear with bridge bony formation and later radiological union which characterized by the bony homogenous, stop forming of external callus formation and remove the FGSR later cortex incorporation (Figures $11 \mathrm{~A} \& 11 \mathrm{~B})$. The radiographic finding of the sheep bony implantation revealed the bony device fixed well by the FGSR with periosteal reaction and new bone formation at the implantation sites to cross the bony device and fix it, at the union of the femoral end and the bony device sclerotic area, the two femoral fragments with the bony device well fixed good alignment with signs of incorporation of the bony device with the recipient femoral bone (Figure 12). 


\section{The Results of the Histopathological} Examination

The histopathological finding of FGSR during fracture healing processing revealed immature new bone formation at the end of the 2 nd week p. o. (Woven bone), then it converted to mature new bone formation at the end of the 4th week p. o. with numerous of osteoblast cells, then the mature bone formation altered to lamellar and compact bone with less of the cavity which filled with highly vascular connective tissues and active osteoblast cells lining the surface of the new trabecular bone formation (Figures 13A \& 13B). While the histopathological finding of the xeno bony sheep implantation which fixed by FGSR revealed immature new bone formation from the recipient femoral bone toward the bony device, then it converted to the mature bony which incorporated with the xeno implantation (Figures $14 \mathrm{~A} \& 14 \mathrm{~B})$.
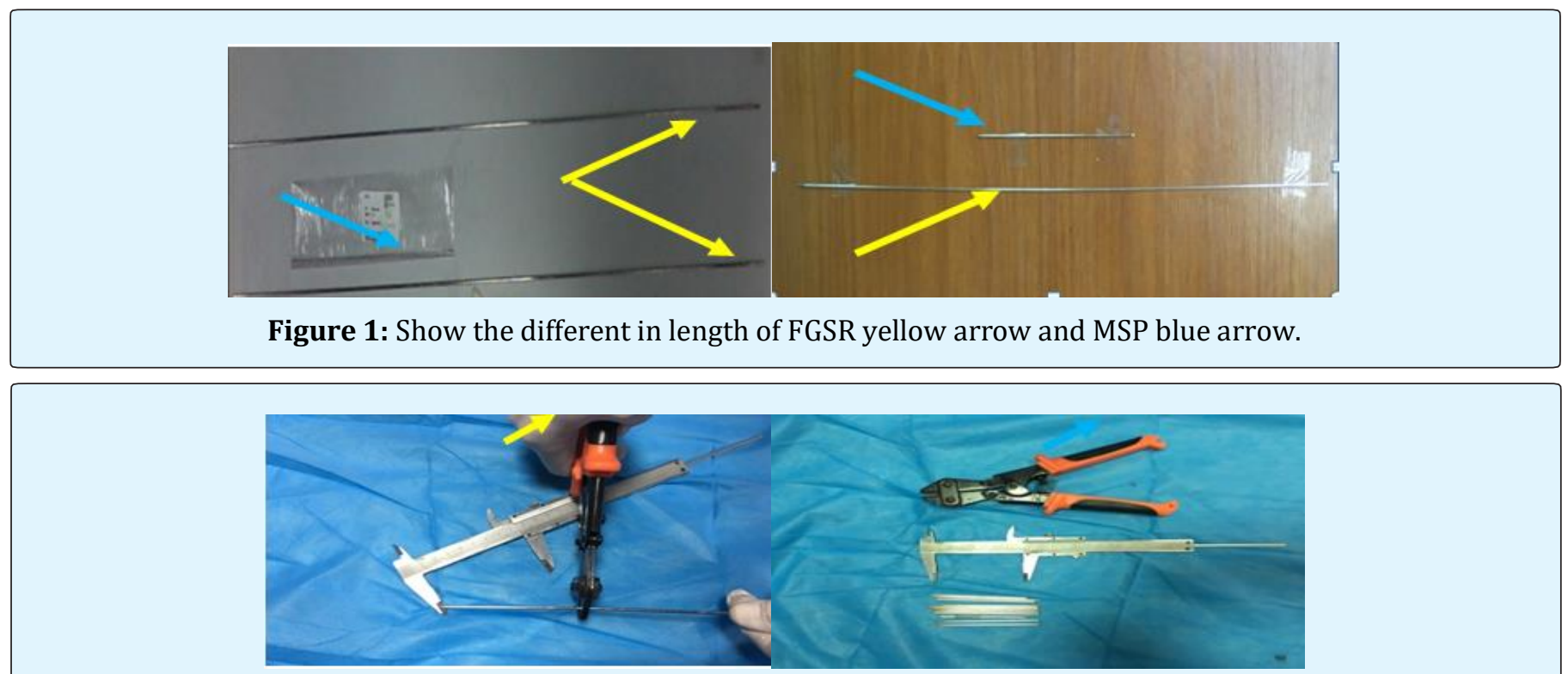

Figure 2: Prepare 10-11 pieces of 9-10 $\mathrm{cm}$ and 2.25-2.5mmprepare the FGSR.

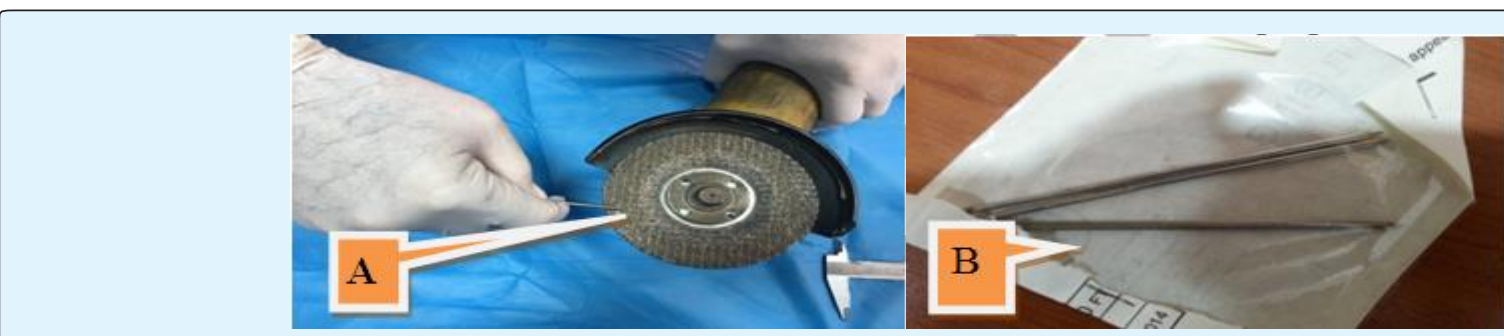

Figure 3: A: Prepare each pin to sharp proximal point and chisel distal end by grinding; B: FGSR sterile by 120c with steam and pressure.

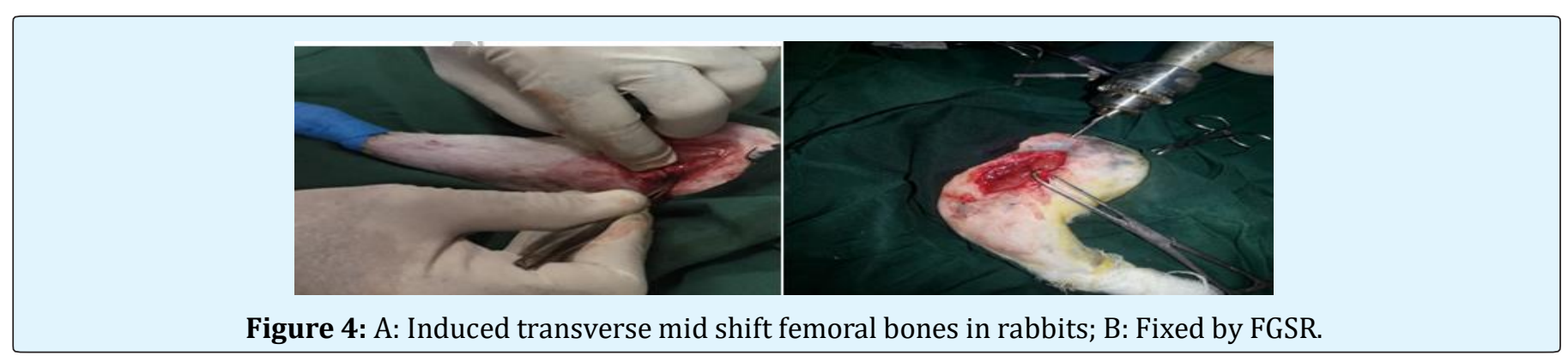




\section{Open Access Journal of Veterinary Science \& Research}

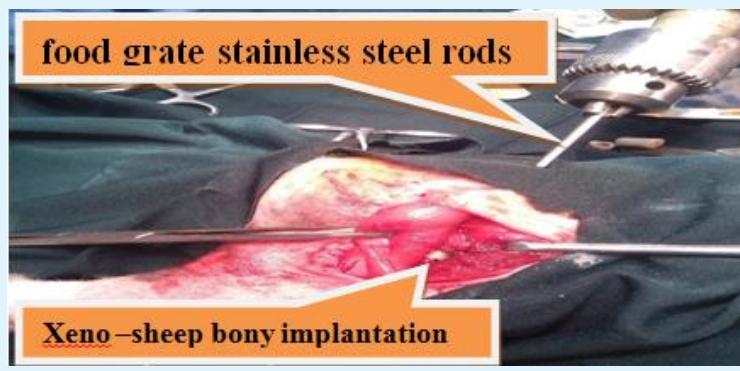

Figure 5: Using of the food grate stainless steel rods in the fixation of the xeno sheep bony implantation in the rabbit's femoral bones.

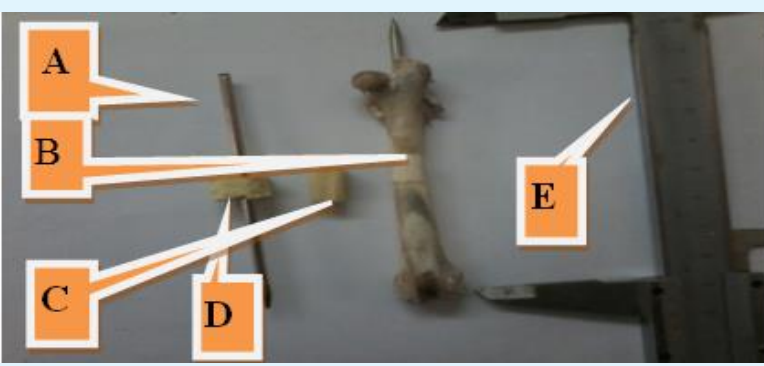

Figure 6 A: FGSR used for internal fixation of different types of grafting.

B: xeno-sheep bony implantation.

C: xeno-bovine bony implantation synthetic bony Nano implantation.

E: caliber for bone measurement.

\begin{tabular}{|c|c|c|c|}
\hline No. & General Details & Food Grate Stainless Steel Rods & Medical Stainless Steel Pinning \\
\hline 1 & Hole length & $100 \mathrm{~cm}$ & $30 \mathrm{~cm}$ \\
\hline 2 & Number of prepared pieces & $10-11$ piece & 3 piece \\
\hline 3 & Total prize for one hole piece & $1 / 2 \$$ & $3-5 \$$ \\
\hline 4 & Prize for one piece & $5-6$ sent & $1-1$ and $1 / 2 \$$ \\
\hline 5 & Oxidation & No change & No change \\
\hline 6 & sterilization & $\begin{array}{c}\text { Boiling water/heat with steam and } \\
\text { pressure/cold sterilization }\end{array}$ & $\begin{array}{c}\text { Boiling water/heat with steam and } \\
\text { pressure/cold sterilization }\end{array}$ \\
\hline 7 & Change after sterilization & No change & No change \\
\hline 8 & Handling and preparation & More easy than the medical & easy \\
\hline
\end{tabular}

Table 1: Table show the main physical and proprieties between the medical stainless steel pinning and the food grate stainless steel rods.

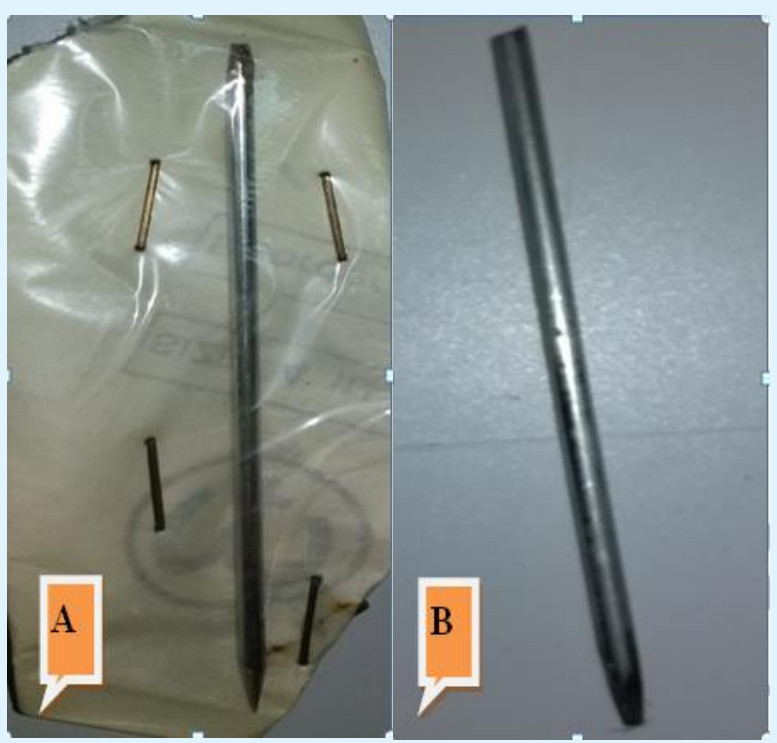

Figure 7: A: Grossly observation for 1 year after sterilization; B: After removing from the fracture case, no change or oxidation or corrosion occurs in the FGSR. 
Open Access Journal of Veterinary Science \& Research

\begin{tabular}{|c|c|c|}
\hline Elements & Medical Stainless Steel Pinning Wt\% & Food Grate Stainless Steel Rods Wt\% \\
\hline $\mathrm{C}$ & $\% 2-\% 0$ & $1 \%-1.5 \%$ \\
\hline $\mathrm{O}$ & $0 \%$ & $\% 1$ \\
\hline $\mathrm{ST}$ & $95.50 \%$ & - \\
\hline $\mathrm{AL}$ & $4.50 \%$ & $1 \%$ \\
\hline $\mathrm{Ti}$ & - & 50 \\
\hline $\mathrm{Ne}$ & $>50 \%$ & 5 \\
\hline $\mathrm{Mo}$ & $8.50 \%$ & 3 \\
\hline
\end{tabular}

Table 2: Lab analysis of the elements ratio between the food grate stainless steel rods and the medical stainless steel pinning.

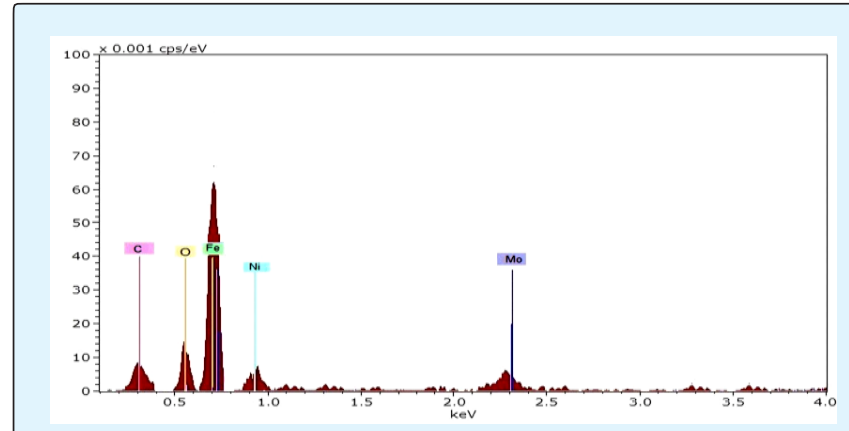

Figure 8: Laboratory analysis of the food grate stainless steel rods.
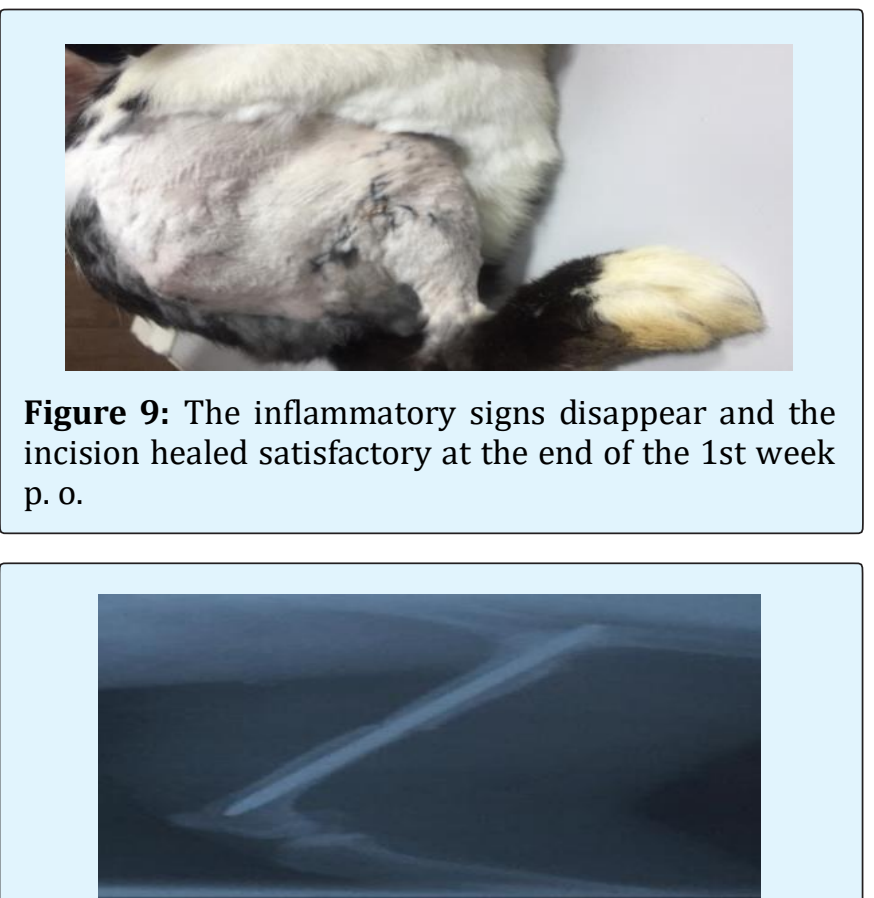

Figure 10: Radiographic image 1st week p. o. of using FGSR in internal fixation of the transverse fracture shows well alignment of fractures bone $\mathrm{F}$. line visible no periosteal reaction appears.

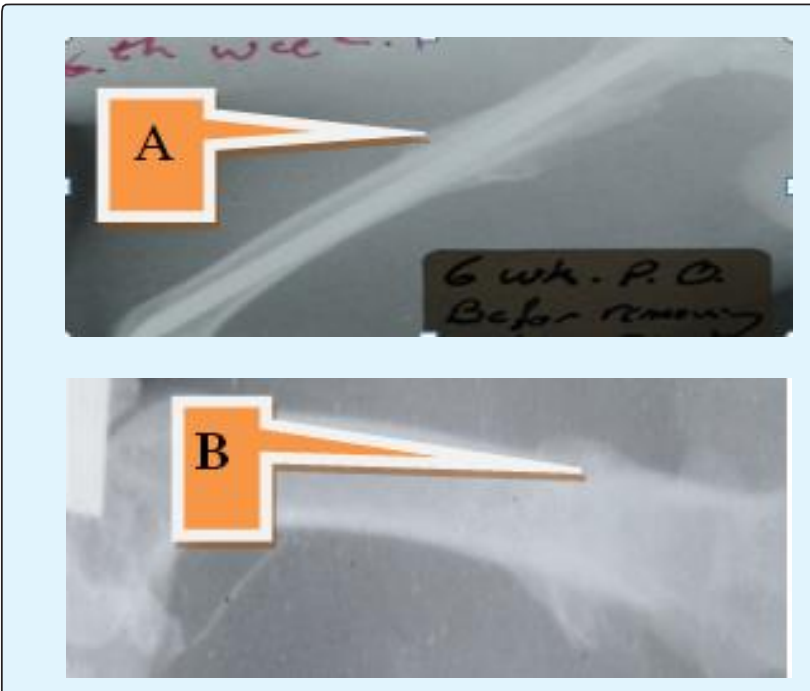

Figure 11: A: Radiological union 6th week p. o. F. line disappear bony callus bridge formation; B: Remove the FGSR and remodeling phase started 8th week p. 0 .

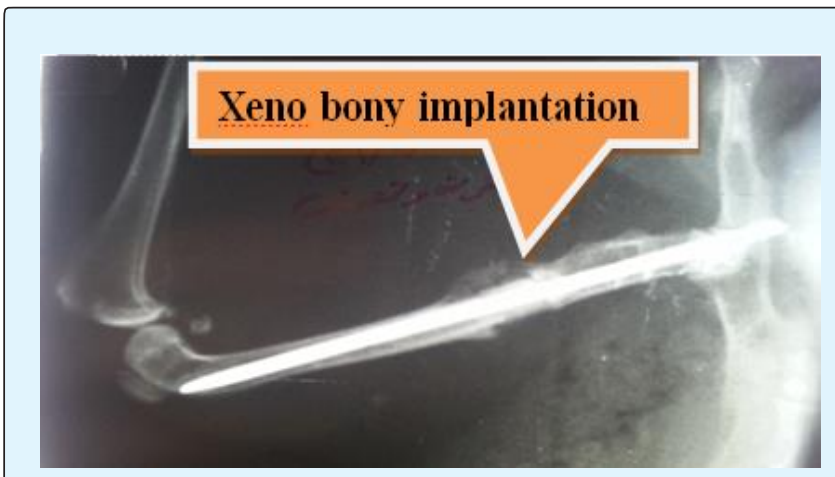

Figure 12: Radiographic image shows the FGSR used for internal fixation of the xeno-sheep bony implantation with signs of callus formation to dross the bony device with sclerotic area at the junction between the bony device and the femoral bone. 


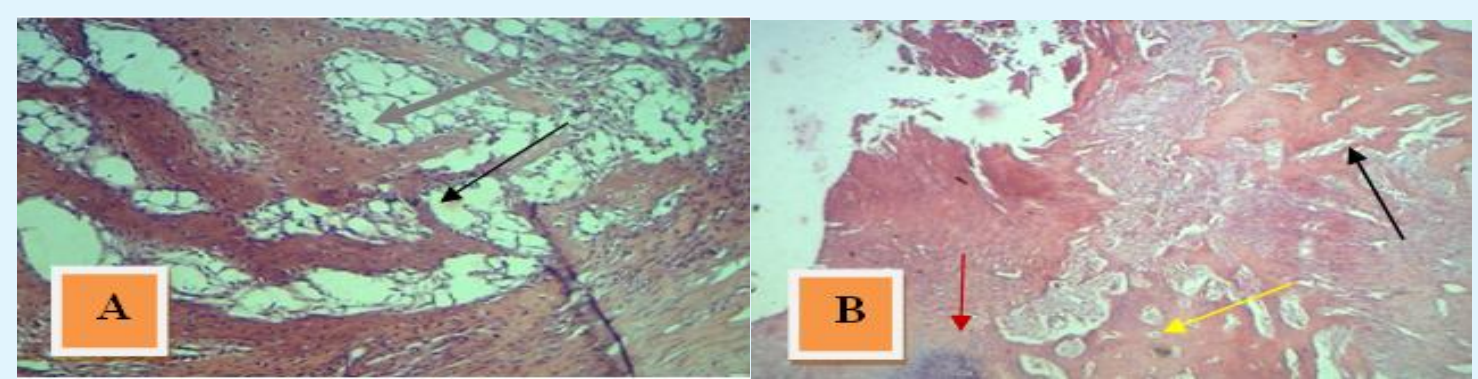

Figure 13: Histopathological changes A. End of 2nd week p. o. revealed immature trabecular bone formation lining with active osteoblast at the bone surface, B: end of two months the F. line filled with mature trabecular bone formation which some converted to lamellar and compact bone still some space filled with connective tissues with area of cartilage formation.

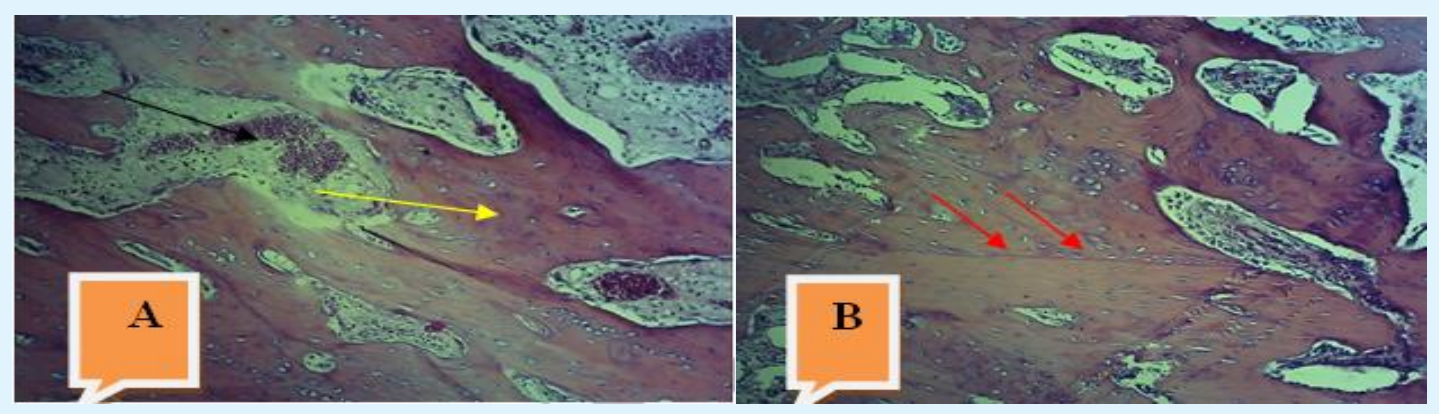

Figure 14: Histopathological section of the xeno sheep bony implantation which fixed by FGSR, A. one and half months p. o. mature new bone formation from the recipient femoral bone toward the xeno bony sheep implantation with large cavity filled with vascular connective tissues, B. three months p. o. boney incorporation between the recipient femoral bone and the xeno sheep bony implantation.

\section{Discussion}

The clinical observation which observed when using the FGSR body emaciation, difficulty in movement, loss of appetite and swelling in the first day post operation then they returned to normal condition in few days after operation, all these signs were normal during the inflammatory phase post operation and similar to inflammatory signs when using IMP as mentioned by Brinker, et al. [15] and Lastayo, et al. [16] and The surgical incision healed normally without complication, and this information agree with Singh, et al. [17], that the inflammatory signs and healing process of the wound are normally occurs after surgical operation in rabbits, and that the animals can used the affected limb in walking running after 3 ed week p. o. with no body rejection or complication.

The experimental animals hold the affected limb during movement then they began to use the limbs in the movement and support the weight 7 days post operation, because the FGSR give support and stability to fracture bones this statement agree with Singh, et al. [17], that lameness disappear gradually especially in stable fracture. Krettek, et al. [8] and Christodoulou, et al. [9] referred that using Intramedullary pinning (IMP) for internal fixation of the femoral fracture is popular, easy to use, gives stability, support and fixation, and all these noted when using FGSR for internal fixation of the induced transverse fractures in rabbits give good results during clinical observation $[8,9]$.

The radiographic finding after using FGSR for internal fixation of the transverse complete fractures in rabbits, that bone healing processing by second bone union which achieved by callus formation around fractures line in the two week p. o. that increase in volume and density and radiological union with disappears of fracture line 4th and 6th week p. o., then remodeling stages continuous until complete fractures healing $[18,19]$. Which appears as homogenous external callus with smooth border, stop forming external callus formation $[15,20]$. With good 
bone alignment and cortical incorporation with the same femoral fractures fragments or the bony implantation $[4,18-22]$.

The histopathological changes during fractures healing processing revealed normal healing which started with immature trabecular formation or woven bone which converted to mature trabecular bone then altered to lamellar and compact bone, all these signs are agree with the results of other workers about internal fixation by in FGSR $[8,9,23]$ that IMP has become the stander of treatment for both femoral and tibial shift fractures, with femur union rate approaching $97 \%$.

The FGSR remain in the place during all healing periods with no signs of infection, or complication, or body rejection and the animal comfortable with the device, and this agree with Voggenreiter, et al. [24] Stiftler, et al. [7], Nazzal, et al. [23], who refer that the IMP generally remains in the bone for the life of the patient and can be removed if it causes pain or other problem.

IM pinning is a surgical procedure to stabilize a broken bone by inserting a metal rod in the hollow medullary canal of the bone. This part of the bone can be used to hold the rod and allow for early movement and weight bearing.IM rods is often the preferred treatment for fractures of the lower extremity long bones that are not close to the joints (bone ends) In these cases, patients can walking much sooner than with other types of fracture treatment $[10,25]$.

A femoral shaft fracture is often treated with IMP. Usually, the rod is made of stainless steel or titanium and they come in different lengths and diameters to fit patients of different ages and heights [12]. FGSR used successfully in stability and support to the bone fragments which help in promote healing fractures as shown during clinical observation, radiographic finding and normal histopathological changes due to early movement and walk of the affected limb with no body rejection or complication or as occurs when using MSP,and these agree with Archibald, et al. [5], Wade, et al. [6], Voggenreiter, et al. [24], Stiftler, et al. [7] Leung, et al. [11], Jonathan Cluett, et al. [10] that IMP lead to stabilized fractures, and attempt to minimized trauma to the soft tissue surrounding a fracture and promote biologic healing, but this note not agree with Jonathan Cluett, et al. [10], which can used in support the fracture bone but not interfere with the normal healing processing, it's important to note that these types of implants don't really speed bone healing and they don't take the place of bone healing [11]. Any metal implant used to stabilize a fracture is designed to hold the fracture in proper alignment while the normal healing process takes place.

The physical and general examination of FGSR which shows easy to clean and sterilization without changes or oxidation before and during and after sterilization and $\mathrm{p}$. o. care, because of the thin transparency layer of chrome oxide adhered to the rods surface not visible besides the presents of lower concentration of carbon which protect the rods from the oxidation and corrosions $[10,12]$.

FGSR provide supporting and stability during fractures healing processing because it content of iron ration about $50 \%$ of its hole content, With no body rejection or complication during the fractures healing processing stages because all the rods elements mixed weal inside the stainless steel combination lead to reduce or absent its effect when used alone [5,6,10,11,24].

The FGSR is a biological inert which not lead to immunity rejection or stimulation as in titanium or medical stainless steel pins because the contents elements concentration are the same or near the normal level of IMP $[11,24]$.

The economic values of the FGSR compare with the MSP because of its low prize and its length which can prepare more than $10-11$ pieces with its easy to find and handling and prepare and give positive results radio graphically that the rods visible and provide stability and strength during fracture healing processing and can share the bone to hold the body weight, also can be removed after radiological bony union formation in which can remove the internal fixation FGSR as in the MSP.

\section{Conclusion}

From the results above FGSR can be used strongly and successfully in the internal fixation of the induced transverse femoral mid shift fractures in rabbits instead of the IMP.

\section{References}

1. Marshall T, Browner BD (2012) Chapter20: Emergency care of musculoskeletal injuries". In Courtney M. Townsend Jr. Sabiston textbook of surgery: the biological basis of modern surgical practice. Elsevier, pp: 480-520.

2. Nazht HH (1992) The Effect of Prostaglandin (PGF2a) on Fracture Healing in Long Bones: Radiological, 


\section{Open Access Journal of Veterinary Science \& Research}

Clinical, and Histological, Studies, A thesis of MSc College of Vet Med Univ of Baghdad.

3. Nazht HH (2000) Effects of Prostaglandin E2 on Bone Resorption in the Remodeling Phase of the Femoral Bone Fractures in Rabbits. A thesis of Ph.D.

4. Hallman M, Thor A (2008) Bone substitutes and growth factors as an alternative/complement to autogenously bone for grafting in implant dentistry. Periodontology 47(1): 172-192.

5. Archibald J (1974) Canine Surgery, 2nd (Edn.), California, American Veterinary Publication, INC.

6. Wade O, Brinker, Donald L, Piermattei Gretchen, Flo L (1990) Hand Book of Small Animal Orthopedics and Fracture Treatment, $2^{\text {nd }}$ (Edn.), W.B. Saunders Company, USA.

7. Stiftler Ks (2004) Internal fracture fixation. Clin Tech Small Anim pract 19(3): 105-113.

8. Krettek C, Miclau TB, lauth M, Lindsey RW, Donow C (1997) Recurrent Rotational Deformity of the Femur after Static Locking of Intramedullary Nails. J Bone Joint Surg IBr 79B: 4-8.

9. Christodoulou A, Terzidis Ploumis A, Metsovitisi S, Koukoulidiis A, Toptsis C (2005) Supracondylar femoral fractures in elderly patients treated with the dynamic condylar serew and the retrograde intramedullary nail: a comparative study of the two methods. Arch orthop Trauma Surg 125(2): 73-79.

10. Jonathan Cluett (2018) Medically reviewed by a board-certified physician.

11. Leung Kwok Sui, Kempf Ivan, Alt Volker, Taglang Gilbert, Haarman HJTM, et al. (2006) Practice of intramedullary locked nails. New developments in techniques and applications. Birkhauser, pp: 100.

12. Ricci WM, Gallagher B, Haidukewych GJ (2009) Intramedullary nailing of femoral shaft fractures: current concepts. J Am Acad Orthop Surg 17(5): 296305.

13. Mamlouk M, Zaniewski J (1999) Materials for Civil and Construction Engineers. Addison Wesley Longman, Inc.

14. Frik EJ, Winer RE, Mosier JE (1948) Treatment of fractures by intramedullary pining. North Am Vet 29: 95-97.
15. Brinker WO, Piermatti DL, Flo GL (1991) Handbook of small animal orthopaedics and fracture treatment. Printed in the United States of America, phiadilphia London, pp: 72-79.

16. Lastayo PC, Winters KM, Hardy M (2003) Fracture healing: bone healing, fracture management, and current concepts related to the hand. J Hand Ther 16(2): 81-93.

17. Singh S, Kumar S, Matti SK (2000) Reconstruction of ulnar segmental defect with autografts and ceramic biomaterials: a scanning electron microscope (SEM) study. Indian J Anim Sci 70: 276-278.

18. Ruedi TP, Buckley RE, Moran CG (2007) A.O. Principles of Fracture Management. ISBN: 3131174420.

19. Teot L (1987) L'enclouage centromedullaire elastique stable chez l'enfant. Cahier d'enseignement de la SOFCOT no 28 Expansion scientific que francaise, Paris, pp: 71-90.

20. Lascombes P (2009) Flexible intramedullary nailing in Childrenlst Edition. Flexible intramedullary nailing in Children Lascombes.

21. Thelen M, Ritter G, Bucheler E (1993) Radiologische Diagnostik der Verletzungen von knochen und Gelenken. Ein leitfaden fur lologen und Traumatologen. Thieme.

22. McRae R, Esser M (2008) Practical fracture Treatment. Churchill Livingstone. $5^{\text {th }}$ (Edn.), Churchill Livingstone.

23. Nazzal A, Lozano-Calderon S, Jupiter JB, Rosenzweig JS, Randolph MA, et al. (2006) A histologic analysis of the effects of stainless steel and titanium implants adjacent to tendons: an experimental rabbit study. J Hand Surg Am 31(7):1123-1130.

24. Voggenreiter G, Leiting $\mathrm{S}$, Brauer $\mathrm{H}$, Leiting $\mathrm{P}$, Majetschak M, et al. (2003) Immuno-inflammatory tissue reaction to stainless-steel and titanium plates used for internal fixation of long bones. Biomaterials 24(2): 247-254.

25. Winquist RA, Hansen ST (1980) Comminuted fractures of the femoral shaft treated by intramedullary nailing. Orthop Clin North Am. 